\title{
An approach to assess the quality of honey using partial least square method
}

\author{
G. Rajalakshmi ${ }^{1}$, A. Gopal ${ }^{2}$, R. Pandian ${ }^{3}$ \\ ${ }^{1,3}$ Sathyabama Institute of Science and Technology, Chennai, India \\ ${ }^{2}$ Central Electronics Engineering Research Institute (CEERI), Council of Scientific and Industrial Research - CSIR \\ Madras complex, Chennai, India
}

\begin{tabular}{l} 
Article Info \\
\hline Article history: \\
Received Oct 7, 2020 \\
Revised May 21, 2021 \\
Accepted Jun 9, 2021 \\
\hline
\end{tabular}

\section{Keywords:}

Adulteration

Chemometrics

PLS

Quantification

Spectrometer

\begin{abstract}
The objective of the present study is to obtain the quantity of honey components such as moisture, glucose, fructose and sucrose in order to access the quality of honey. The tested honey samples are authenticated if the characteristics of a pure honey. The average ratio of $56 \%$ fructose to $44 \%$ glucose, but the ratios in the individual honeys ranged from a high of $64 \%$ fructose and $36 \%$ glucose to a low of $50 \%$ fructose and $50 \%$ glucose. The contents such as fructose and sucrose in honey is due to the presence of invertase enzymes. The organic acids present in the honey is responsible for the flavor and stability against the contamination of honey due to microorganisms. The natural food items are adulterated intentionally to increase the quantity and there by the quality gets affected. The main adulterants added in honey are sucrose, corn syrup, sugar syrup and jaggery syrup. The quantification deals in finding out the amount of basic constituents present in pure honey and adulterated honey using Fourier transform infrared (FTIR) spectrometer with the multivariate analysis and validating the same using chemical analysis method. The partial least square model is used in predicting the constituents of the samples.
\end{abstract}

This is an open access article under the CC BY-SA license.

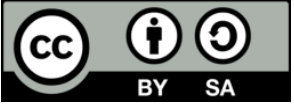

\section{Corresponding Author:}

G. Rajalakshmi

Sathyabama Institute of Science and Technology

Chennai, India

Email: rose_raji@yahoo.com

\section{INTRODUCTION}

Honey is a natural product obtained by honey bees from the nectar of flowers or excretions of plant sucking insects. Honey is a substance with the combinations of various substances such as carbohydrates, moisture, proteins, acids, hydroxymethylfurfural (HMF), and ashes [1]. Honey has a content 85\% carbohydrates, 15 water, $0.3 \%$ proteins, $0.2 \%$ ashes, and less quantities of vitamins and amino-acids as well as other constituents in low levels of concentration [2], [3]. The composition and characteristics of honey varies due to botanical and geographical origin or the nectar used by the bees to due to which honey seems to be a complex mixture by nature. The floral origin determines the feature of the honey. A familiar problem in many parts of the world is adulteration of food stuff with different adulterants irrespective of the status of the country with respect to the economy. The adulteration is either intentional or unintentional rather to increase the quantity of the food substance. The addition of sucrose, beet syrup, corn syrup, molasses, banana, or any other harmless or harmful substances. This lead to the nutritional and health problems on consumers leading to the brutal influence on the national and international trade opportunities of the product [4]-[6]. Several honey purity tests conducted for the determination of sugar profile level by spectrophotometer, sugar profile 
by gas chromatography, water content by hand held refractometer, determination of hydrogen peroxide and $\mathrm{pH}$ value by $\mathrm{pH}$ meter [7], [8].

Fourier transform infrared (FTIR) spectroscopy is a technique which is used to obtain infrared spectrum of absorption, emission, and photo conductivity of solid, liquid, and gas. It is used to detect different functional groups in PHB. FTIR spectrum is recorded between 4000 and $400 \mathrm{~cm}^{-1}$. FTIR uses the mathematical process to translate the raw data into the actual spectrum. FTIR method is used to obtain the infrared spectrum of transmission or absorption of a sample. Depending on the infrared absorption frequency range $600-4000 \mathrm{~cm}^{-1}$, the specific molecular groups prevailing in the sample will be determined through spectrum data in the automated software of spectroscopy [9]-[11]. The mathematical model and statistical procedures can be used in extracting information using Chemo metrics from the measurements obtained from a chemical system. There are two types of data, univariate which contains one variable to measure and the other for prediction. Multivariate data contains more variables to measure and predict. The chemo metric analysis starts with measuring and collection of data. The relevant information are extracted from the measured data (spectrometric data or chromatographic) using mathematical and statistical methods which facilitates in decision making. The next aim is to preprocess the obtained data to remove variation among the data that is not related to the analytical information. Typical preprocessing includes baseline correction, mean centering, normalization, orthogonal signal correction, multiplicative scatter correction, and savitsky-golay derivation. Many different methods for performing multivariate data analysis is available are principal component analysis (PCA), partial least squares (PLS), misclassification rate (MCR), and neural networks (NNs) [12], [13]. The qualitative analysis includes obtaining classification models followed by prediction and validation, whereas the quantitative analysis works with prediction models followed by validation. The quantification of common adulterants seen in milk samples using. The calibration is performed using leastsquares support vector machine for the data obtained from Near-infrared spectroscopy using diffuse reflectance. The chemo metrics combined with Near-infrared spectroscopy is used to detect adulteration in honey using since there is a non-linear behaviour present when different adulterants are in the same data set, using the linear methods such as PLSR is difficult [14], [15].

Multivariate analysis (MVA): Multivariate data analysis determines the relationships existing between many variables. The multivariate analysis is rarely used to production processes but primarily applied in technical groups and laboratories. The MVA offers an insight in improving the performance of the process and product development. While analyzing the uni variate complex systems, the uni variate statistics leads to failure causing the process upset. The multivariate analysis tools helps engineers and production managers to understand the behaviour of the process and implement strategies in more robust control to control the quality, maximize the yield, run the processes closer to limits, to use components with lower cost, reduce energy, cycle time and minimize the waste [16]-[18].

Partial least squares (PLS): PLS is a widely used technique in chemo metrics, especially in the case where the number of independent variables is significantly larger than the number of data points [19], [20]. Partial least squares is a popular method for soft modelling in industrial applications. Partial least squares is a method for constructing predictive models when the factors are many and highly col-linear. A great advantage of PLS regression over classic regression are the available charts that describe the data structure. PLS regression is also used to build predictive models [21], [22]. The predicted values.

\section{RESEARCH METHOD}

The research work aims at finding the quality of honey samples using chemometric analysis. The contituents of honey and the adulteration in honey has been spotted using various chromatographic methods such as gas chromatography, high performance liquid chromatography and other physio chemical tests which are fast and accurate. The study from the previous research works reveals that application of multivariate data analysis such as canonical variate analysis, principal component analysis, partial least square regression, principal component regression. Linear discriminant analysis are promising methods of analysis for honey samples in identifying and developing a model to quantify the constituents of honey.

The different honey samples such as hill Honey; branded Honey were collected, $150 \mathrm{ml}$ of honey is taken from a sample of 1-litre of hill honey. Sugar syrup is prepared using $150 \mathrm{ml}$ of distilled water with 300 gm of sugar. $150 \mathrm{ml}$ of honey is mixed with $15 \mathrm{ml}$ of sugar syrup till the solution becomes homogeneous. The concentration of sugar syrup is increased as $20 \%, 30 \%$ and $40 \%$ with the hill honey. The spectral data is obtained for various honey samples, Sugar syrup, honey adulterated with sugar syrup with increased concentrations. The spectral data is acquired using FTIR spectrometer. The generalized block diagram is shown in Figure 1, which describes the process involved in the research work. The article illustrates only a part of the work rather than the work as whole. 


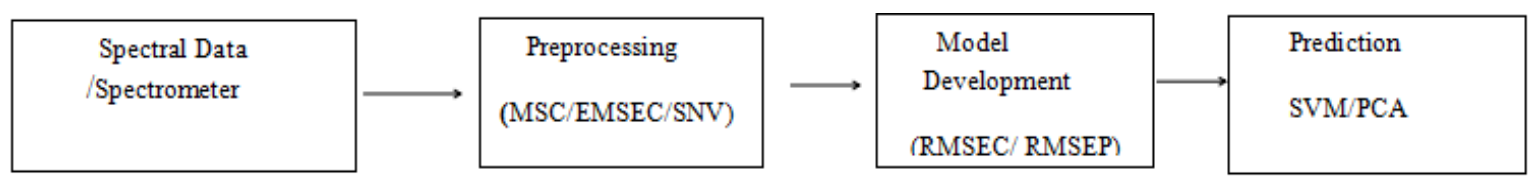

Figure 1. Generalized block diagram of the research work

The identification of the finger print regions of the key moisture, glucose, fructose and sucrose is followed by the preprocessing of the spectral data obtained for the samples of honey. The key constituents present in honey in larger composition are moisture, glucose, fructose and sucrose. The composition of moisture is measured to assess the shelf life of honey. The composition of glucose and fructose must be predicted to find the ratio between glucose and fructose whose allowable range is 1 for an authentic honey. The quantitative analysis of the components is performed in the research work in order to determine whether there is a change in the composition of the raw honey and the samples where the adulterant is added intentionally. Thus, a calibration model was developed using PLS to predict the constituents present in honey based on the spectral data obtained from the FTIR spectroscopy. The calibration curve is plotted between the reference values and predicted values for the acquired data from the samples to find out the RMSE and $\mathrm{R}^{2}$ values. The detailed explanation is described in results and discussions section.

\section{RESULTS AND DISCUSSION}

The spectra of pure honey show the absorbance band 1062.45, 1646, $3372.31 \mathrm{~nm}$ corresponds to glucose, fructose and sucrose and the sample is pure hill honey containing $100 \%$ hill honey and $0 \%$ sugar syrup. The spectra of sugar syrup show the absorbance band at 1046.36, 1645.94, $3404.48 \mathrm{~nm}$ corresponds to glucose, fructose and sucrose and the sample is pure sugar syrup containing 0\% hill honey and $100 \%$ sugar syrup. The spectra of hill honey with increasing concentration of sugar syrup show the absorbance and $1054.40,1645.95,2932.68,3388.40 \mathrm{~nm}$ corresponds to glucose, fructose and sucrose and the sample contains increasing concentration of sugar syrup at $10 \%, 20 \%, 30 \%, 40 \%$ respectively. Partial least square analysis is applied in addition to the FTIR spectra of pure honey. The concentrations of the main constituents such as moisture and the main sugars such as glucose, fructose and sucrose are obtained using PLS technique. The chemical analysis is performed and used as a reference value to validate the FTIR predictions of the concentration of the main sugars. The results thus obtained has proved that the chemo metric analysis of linked with FTIR spectroscopy can be used to predict the contents of moisture, sugar [23], [24].

\subsection{Prediction of moisture}

The samples such as hill honey named as HH1, HH2, HH3, HH4, HH5, HH6 are analyzed using the FTIR spectrometer, out of which few samples are used for prediction and the remaining for validation. The graph is plotted for the predicted values vs reference values to obtain the concentration of the moisture content in the samples. From the Figure 2, it is observed that the RMSE $=0.023$ and $\mathrm{R}^{2}=0.9975$ are the predicted values and $\mathrm{RMSE}=0.023$ and $\mathrm{R}^{2}=0.9989$ for the reference. The Table 1 shows the reference value, predicted values and the deviation from the reference values which is obtained from the chemical analysis in predicting the quantity of moisture. The score plot for the PLS calibration curve predicting the content of moisture in Honey is shown in Figure 3. The score plot is plotted for the samples of hill honey, branded honey, honey adulterated with sugar syrups in different concentrations as shown in Figure 4. The samples mentioned in the list are discriminated clearly in the score plot. The score plot is plotted for the factor-1 and factor-2.The score plot gives information about sample proximity and data set structure [25].

\subsection{Prediction of glucose, fructose and sucrose}

The samples such as hill honey named as HH1, HH2, HH3, HH4, HH5, HH6 along with the branded honey samples named as $\mathrm{BH} 1, \mathrm{BH} 2, \mathrm{BH} 3, \mathrm{BH} 4, \mathrm{BH} 5, \mathrm{BH} 6$ then the sugar syrups added to the hill honey with different concentrations labeled as HS1, HS2, HS3, HS4, HS5, HS6 are analyzed using the FTIR spectrometer, out of which few samples are used for prediction and the remaining for validation. The graph is plotted for the predicted values vs reference values to obtain the concentration of the glucose content in the samples. From the Figure 5, it is observed that the RMSE $=0.013$ and $\mathrm{R}^{2}=0.9973$ are the predicted values and $\mathrm{RMSE}=0.0258$ and $\mathrm{R}^{2}=0.9921$ for the reference. The Table 1 shows the reference value, predicted values and the deviation from the reference values which is obtained from the chemical analysis in predicting the quantity of glucose [26], [27]. 


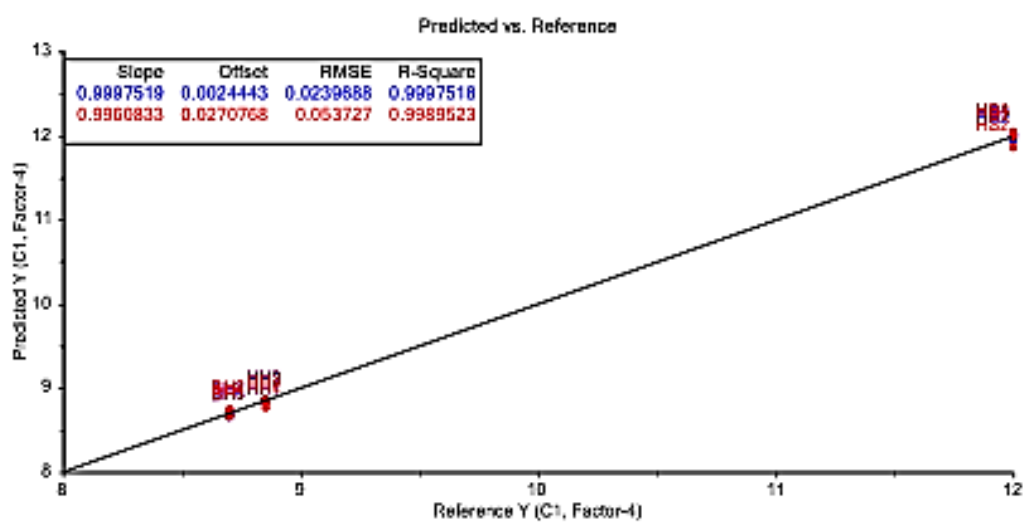

Figure 2. Partial least squares calibration curve predicting the content of moisture in honey

Table 1. The prediction vs reference values of moisture and glucose

\begin{tabular}{cccccccc}
\hline Sample & $\begin{array}{c}\text { Reference } \\
\text { value } \\
\text { Moisture }\end{array}$ & $\begin{array}{c}\text { Predicted } \\
\text { value }\end{array}$ & Deviation & Sample & $\begin{array}{c}\text { Reference } \\
\text { value } \\
\text { Glucose }\end{array}$ & $\begin{array}{c}\text { Predicted } \\
\text { value }\end{array}$ & Deviation \\
\hline HH4 & 6.3500 & 6.3475 & 0.0099 & HH4 & 8.8500 & 8.815 & 2.3918 \\
HH5 & 6.3500 & 5.7937 & 0.6001 & HH5 & 8.8500 & 8.815 & 2.3918 \\
BH5 & 6.9000 & 6.8378 & 0.0154 & BH5 & 8.7000 & 8.9197 & 0.0867 \\
BH6 & 6.9000 & 6.8799 & 0.0104 & BH6 & 8.7000 & 8.8321 & 0.0489 \\
HS5 & 6.9000 & 6.8935 & 0.0065 & HS5 & 12.000 & 12.0273 & 0.0287 \\
HS6 & 6.9000 & 6.8812 & 0.0091 & HS6 & 12.000 & 12.0432 & 0.0428 \\
\hline
\end{tabular}

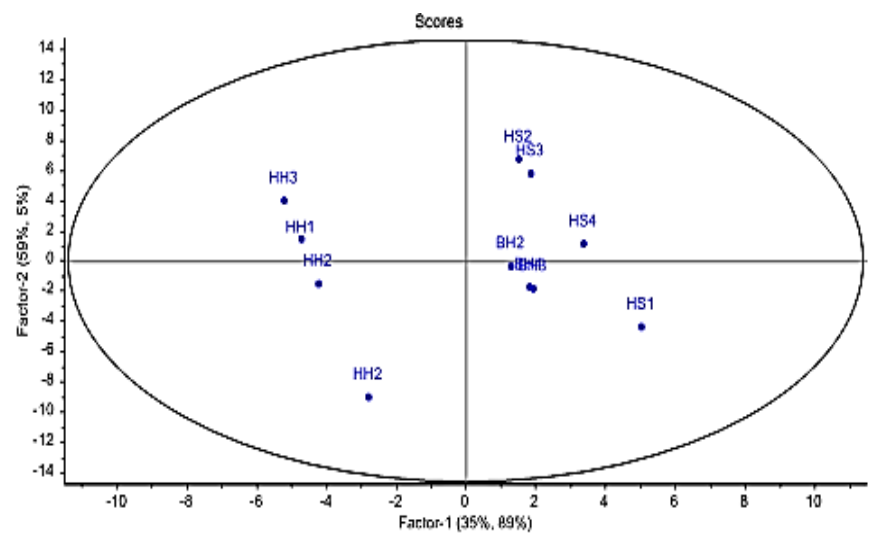

Figure 3. Partial least squares calibration curve predicting the content of moisture in honey

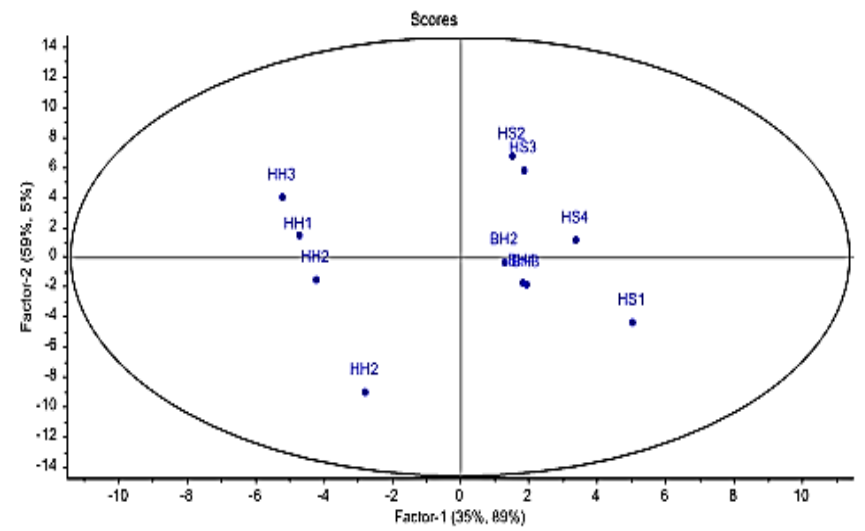

Figure 4. Score plot for the FTIR spectral data of hill honey, branded honey, adulterated honey 


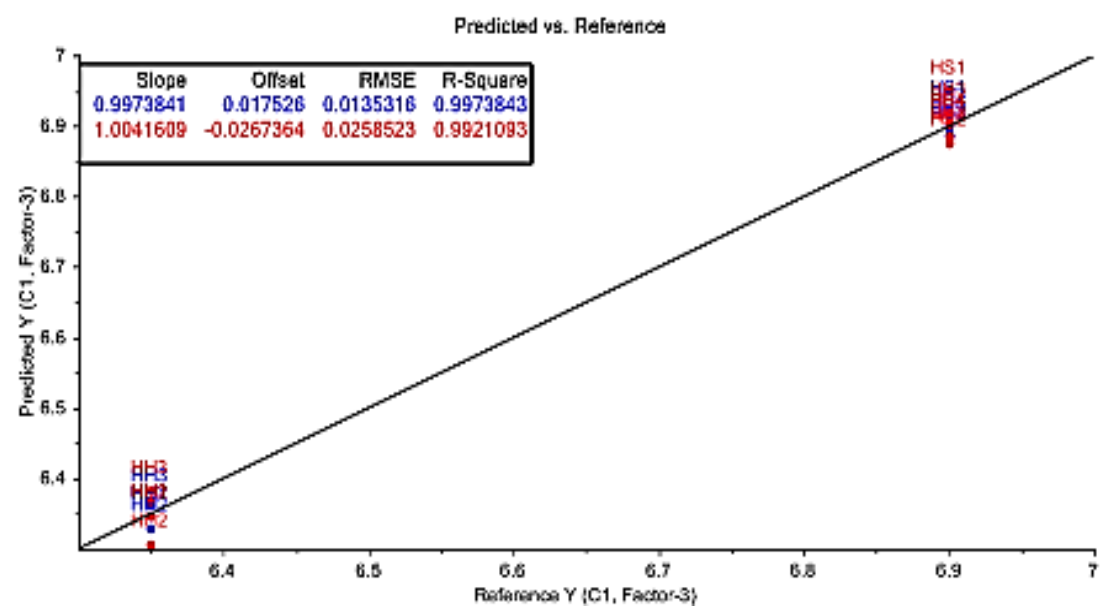

Figure 5. Partial least squares calibration curve predicting the content of glucose in honey

The graph is plotted between the predicted values and reference values to obtain the concentration of the fructose content in the samples. From the Figure 6, it is observed that the RMSE $=0.627$ and $\mathrm{R}^{2}=0.9983$ are the predicted values and $\mathrm{RMSE}=1.274$ and $\mathrm{R}^{2}=0.9979$ for the reference. The Table 2 shows the reference value, predicted values and the deviation from the reference values which is obtained from the chemical analysis in predicting the quantity of fructose [28].

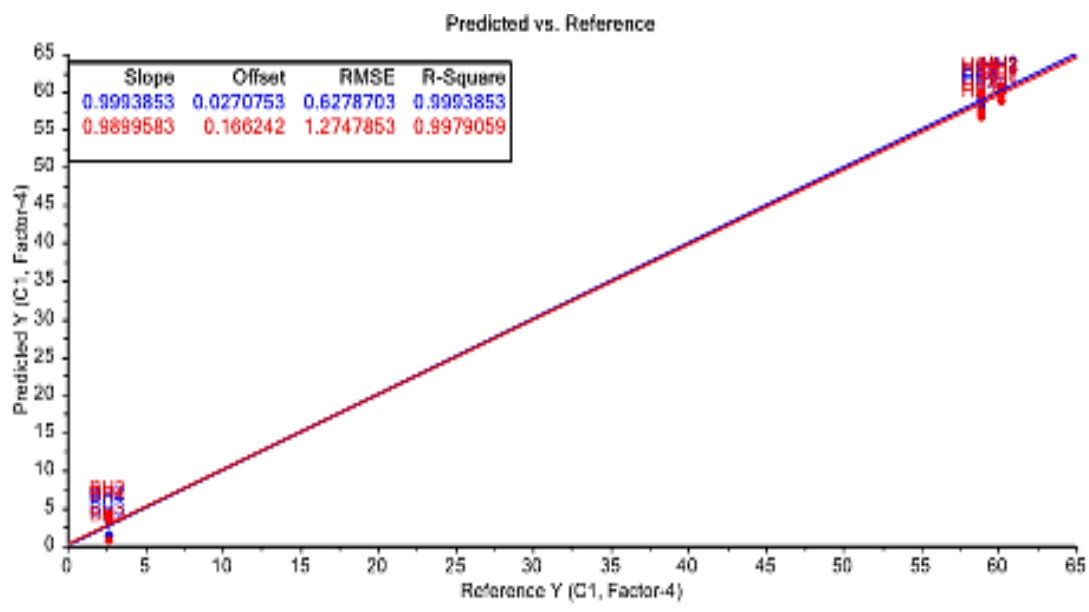

Figure 6. Partial least squares calibration curve predicting the content of fructose in honey

Table 2. The prediction vs reference values of fructose and sucrose

\begin{tabular}{cccccccc}
\hline Sample & $\begin{array}{c}\text { Reference } \\
\text { value } \\
\text { Fructose }\end{array}$ & $\begin{array}{c}\text { Predicted } \\
\text { value }\end{array}$ & Deviation & Sample & $\begin{array}{c}\text { Reference } \\
\text { value }\end{array}$ & $\begin{array}{c}\text { Predicted } \\
\text { value } \\
\text { Sucrose }\end{array}$ & Deviation \\
\hline HH4 & 60.2000 & 59.6728 & 1.0006 & HH4 & 2.4000 & 1.9562 & 0.5367 \\
HH5 & 60.2000 & 135.8681 & 53.4479 & HH5 & 2.4000 & 0.9773 & 22.9930 \\
BH5 & 2.7000 & 8.5649 & 1.8865 & BH5 & 2.5000 & 4.1670 & 0.8689 \\
BH6 & 2.7000 & 6.0807 & 1.1251 & BH6 & 2.5000 & 3.4932 & 0.5565 \\
HS5 & 58.9000 & 59.8127 & 0.6687 & HS5 & 30.2000 & 30.4123 & 0.3775 \\
HS6 & 58.9000 & 60.9223 & 0.9544 & HS6 & 30.2000 & 30.4823 & 0.4885 \\
\hline
\end{tabular}

Figure 6 shows the plot between the predicted value and reference value using PLS model in predicting the sucrose content in the samples of hill honey, branded honey and hill honey adulterated with sugar syrups in different concentrations. From the Figure 7, it is observed that the RMSE $=0.160$ and $\mathrm{R}^{2}=0.999$ are the predicted values and $\mathrm{RMSE}=0.810$ and $\mathrm{R}^{2}=0.9972$ for the reference. The Table 2 shows the 
reference value, predicted values and the deviation from the reference values which is obtained from the chemical analysis in predicting the quantity of fructose.

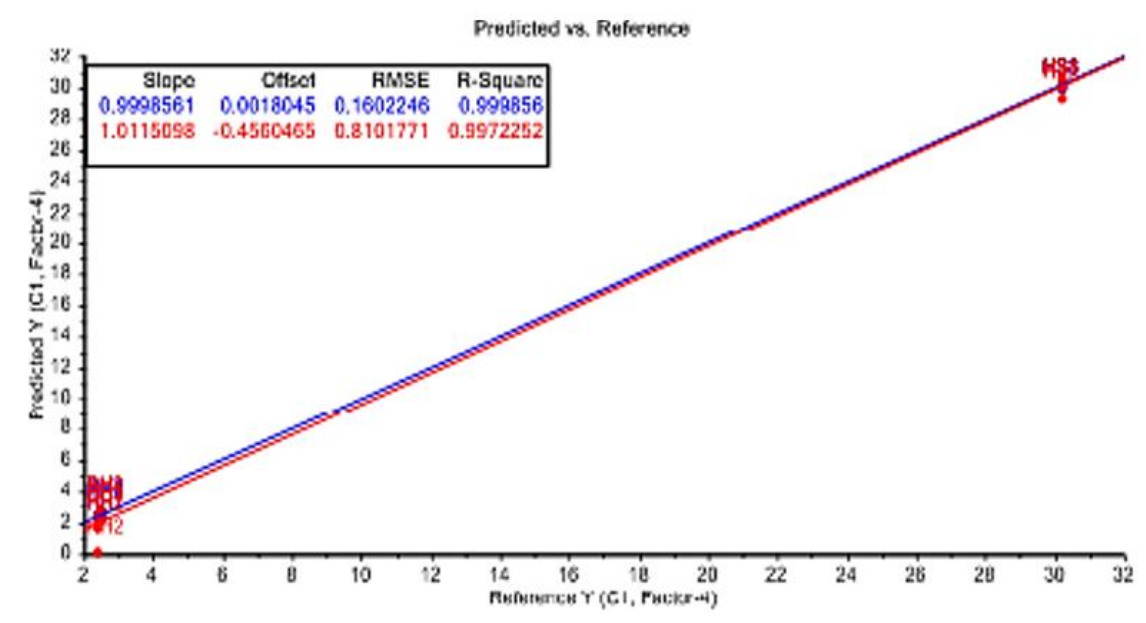

Figure 7. Partial least squares calibration curve predicting the content of sucrose in honey

\section{CONCLUSION}

The regression models were developed using PLS method to predict the quantity of constituents such as moisture, glucose, fructose and sucrose. The RMSE value of 0.023 and $\mathrm{R}^{2}$ of 0.9975 and the predicted values and $\mathrm{RMSE}=0.023$ and $\mathrm{R}^{2}=0.9989$ and the reference for the moisture content. The $\mathrm{RMSE}=0.627$ and $\mathrm{R}^{2}=0.9983$ are the predicted values and $\mathrm{RMSE}=1.274$ and $\mathrm{R}^{2}=0.9979$ and $\mathrm{r}$ the reference for glucose content. The $\mathrm{RMSE}=0.627$ and $\mathrm{R}^{2}=0.9983$ are the predicted values and $\mathrm{RMSE}=1.274$ and $\mathrm{R}^{2}=0.9979$ for the reference for fructose content. The $\mathrm{RMSE}=0.160$ and $\mathrm{R}^{2}=0.999$ are the predicted values and $\mathrm{RMSE}=0.810$ and $\mathrm{R}^{2}=0.9972$ for sucrose. The composition of reducing sugars in pure samples of honey must be less than $60 \%$ as per European Standards. Due to the high humidity the $\%$ the reducing sugars is lower than $60 \%$ in a country like Malaysia which falls in a tropical region. But still the ratio between fructose/glucose observed for pure honey vary from $0.9-1.35$. The total percentage of reducing sugars in pure and adulterated honey might have the indistinguishable characteristics. One of the studies reveals that the level of sucrose exceeding $5 \%$ but not more than $5 \%$ has been confirmed by the European standard for pure honey. The allowable moisture content in pure honey is up to $20 \%$. The permissible value of glucose ranges between 22.89 and $40.75 \%$, the acceptable range of fructose is from 30.91 to $44.26 \%$, and tolerable value of sucrose ranges from 0.25 to $7.59 \%$. The spectra obtained from the FTIR has shown a promising result in finding out the amount of constituents that contributes much in samples of honey and adulterated honey with the corn syrup. The obtained result shows that there is no much deviation in the quantity of moisture, glucose fructose and sucrose from the allowable range to the obtained results using multivariate model using FTIR spectroscopy technique.

\section{ACKNOWLEDGEMENTS}

I would like to thank the management of Sathyabama Institute of Science and Technology for providing the FTIR, spectrometer to test the honey samples and providing me the opportunity to pursue the research work in the esteemed institution.

\section{REFERENCES}

[1] E. F. Boffoa, L. A. Tavares, A. C. T. Tobias, M. M. C. Ferreira, and A. G. Ferreira, "Identification of components of Brazilian honey by H NMR and classification of its botanical origin by chemometric methods," LWT Food Science and Technology, vol. 49, no. 1, pp. 55-63, 2012, doi: 10.1016/j.1wt.2012.04.024.

[2] S. Saxena, S. Gautam, and A. Sharma, "Physical, biochemical and antioxidant properties of some Indian honeys," Food Chemistry, vol. 118, no. 2, pp. 391-397, 2010, doi: 10.1016/j.foodchem.2009.05.001.

[3] G. F. Fairchild, O. Capps, and J. P. Nichols, "Impact of Economic Adultera-tion on the US Honey Industry," WAEA 2000 Annual Meeting, Vancouver, British, Columbia, 2000, doi: 10.22004/ag.econ.36358. 
[4] A. A. Ayansola and A. D. Banjo, "Physico-chemical Evaluation of the Authenticity of Honey Marketed in Southwestern Nigeria,” J. Basic. Appl. Sci. Res., vol. 1, no. 12, pp. 3339-3344, 2011.

[5] M. Kartheek, A. A. Smith, A. K. Muthu, and R. Manavalan, "Determination of Adulterants in Food: A Review," J. Chem. Pharm. Res., vol. 3, no. 2, pp. 629-636, 2011.

[6] T. Dearing, "Fundamentals of Chemometrics and Modeling," CPAC, University of Washington. [Online], Available: https://depts.washington.edu/cpac/Activities/Meetings/documents/DearingFundamentalsofChemometric s.pdf.

[7] R. Gopalakrishnan, A. Gopal, A. Kumar, and A. D. Kumar, "Identification of Moisture, Glucose, Sucrose, Fructose region in Honey sample using NIR spectroscopy," 2017 Third International Conference on Sensing, Signal Processing and Security (ICSSS), 2017, pp. 389-391, doi: 10.1109/SSPS.2017.8071625.

[8] J. M. B. de Sousa et al., "Sugar profifile, physicochemical and sensory aspects of monoflfloral honeys produced by different stingless bee species in Brazilian semi-arid region," LWT - Food Science and Technology, vol. 65, pp. 645-651, 2016, doi: 10.1016/j.lwt.2015.08.058.

[9] A. Pu'scion-Jakubik, M. H. Borawska, and K. Socha, "Modern Methods for Assessing the Quality of Bee Honey and Botanical Origin Identifification," Foods, vol. 9, no. 8, 2020, doi: 10.3390/foods9081028.

[10] M. Ohmenhaeuser, Y. B. Monakhova, T. Kuballa, and D. W. Lachenmeier, "Qualitative and Quantitative Control of Honeys Using NMR Spectroscopy and Chemometrics," International Scholarly Research Notices, vol. 2013, pp. 1-9, 2013, doi: 10.1155/2013/825318.

[11] K. Kanazawa et al., "Computer aided diagnosis for pulmonary nodules based on helical CT image," Computerized Medical Imaging and Graphics, vol. 22, no. 2, pp. 157-167, 1998, doi: 10.1016/S0895-6111(98)00017-2.

[12] D. T. Lin and C. R. Yan, "Lung nodules identification rules extraction with neural fuzzy network," Proceeding of the 9th International Conference on Neural Information Processing, 2002, vol. 4, pp. 2049-2053, doi: 10.1109/ICONIP.2002.1199035.

[13] G. P. Zhang, "Neural networks for classification survey," IEEE Transactions on Systems, Man, and Cybernetics, Part C: Applications and Reviews, vol. 30, no. 4, pp. 451-446, 2002, doi: 10.1109/5326.897072.

[14] C. Deng, W. Lin, and J. Cai, "Content-Based Image Compression for Arbitrary-Resolution Display Devices," IEEE Transactions on Media, vol. 4, no. 4, pp. 1127-1139, 2012, doi: 10.1109/TMM.2012.2191270.

[15] I. Maglogiannis, C. Doukas, G. Kormentzas, and T. Pliakas, "Waveleth ROI coding support for mobileaccess to DICOM images over heterogeneous radio networks," Trans. Inform. Technol. Biomed., vol. 13, no. 4, pp. 458-466, 2009, doi: 10.1109/TITB.2008.903527.

[16] D. Dragan and D. Ivetic, "An approach to DICOM extension for medical image streaming," International scientific book, pp. 25-35, 2009.

[17] R. A. Osorniorios, "Identification of positioning system for industrial application using neural network," J Sci Ind India, vol. 76, pp. 141-144, 2017.

[18] W. J. Choi and T. S. Choi, "Automated Pulmonary Nodule Detection Based on Three-Dimensional Shape-Based Feature Descriptor," Computer Methods and Programs in Biomedicine, vol. 113, no. 1, pp. 37-54, 2014, doi: 10.1016/j.cmpb.2013.08.015.

[19] D. M. Peña, S. Luo, and A. M. S. Abdelgader, "Auto Diagnostics of Lung Nodules Using Minimal Characteristics Extraction Technique," Diagnostics, vol. 6, no. 1, 2016, Art. no. 13, doi: 10.3390/diagnostics6010013.

[20] S. Bravani and K. Thanushkodi, "A survey on coding algorithms in medical image compression," International Journal on Computer Science and Engineering, vol. 2, no. 5, pp. 1429-1434, 2010.

[21] Y. Y. Chen, "Medical image compression using DCT-based subband decomposition and modified SPIHT data organization," International journal of medical informatics, vol. 76, no. 10, pp. 717-725, 2007, doi: 10.1016/j.ijmedinf.2006.07.002.

[22] B. H. AlQarni and A. S. AlMogren, "Reliable and energy efficient protocol for MANET multicasting," Journal of Computer Networks and Communications, vol. 2016, pp. 1-13, 2016, doi: 10.1155/2016/9146168.

[23] S. Dahal and N. Ray, "Enhanced multicast routing protocol in MANET," International Conference on Information Technology (ICIT), 2016, pp. 6-11, doi: 10.1109/ICIT.2016.015.

[24] A. Chakrawarti, V. Malviya, and P. Sharma, "A novel approach for adaptive multicast routing in MANET," International Conference on I-SMAC (IoT in Social, Mobile, Analytics and Cloud) (I-SMAC), 2017, pp. 169-174, doi: 10.1109/I-SMAC.2017.8058332.

[25] B. Yang, Z. Wu, Y. Shen, and Y. Fan, "Multicast delivery delay in general two-hop relay MANETs," International Conference on Networking and Network Applications (NaNA), 2017, pp. 100-103, doi: 10.1109/NaNA.2017.44.

[26] H. Pan, E. Hou, and N. Ansari, "M-NOTE: A multi-part ballot based-voting system with clash attack protection," in 2015 IEEE International Conference on Communications (ICC), London, 2015, pp. 7433-7437, doi: 10.1109/ICC.2015.7249514.

[27] H. Pan, E. Hou, and N. Ansari, "Re-note: an e-voting scheme based on ring signature and clash attack protection," in 2013 IEEE Global Communications Conference (Globecom), 2013, pp. 867-871, doi: 10.1109/GLOCOM.2013.6831182.

[28] T. T. M. Delsy, N. M. Nandhitha, and B. S. Rani, "Feasibility of spectral analysis techniques for disruption analysis in Aditya tokamak," International Journal of Engineering and Technology, vol. 7, no. 4, pp. 3843-3846, Dec. 2018 . 


\section{BIOGRAPHIES OF AUTHORS}

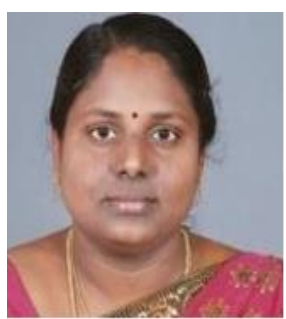

G. Rajalakshmi has completed the under gradutate program from Sethu Institute of Technology, Madurai Kamaraj University in the discipline of Instrumentation and Control Engineering in the year 1999. The master's degree was attained in Electronics \& Control Engineering in the year 2007, form Sathyabama University.She started her carrier as a lecturer which is her passion in an Engineering College in the department of Electronics and Instrimentation Engineering. Now she is working as an Assistant Professor in the Department of Electronics and Instrumentation Engineering, Sathyabama Institute of Science \& Technology, Chennai, pursuing the Ph.D programme in Signal processing. The author is much interested in the real time applications based research work, which could serve the society also. The adulteration has been a massive problem in the food industries which paved the way for her to undergo the research work in quality analysis of food substances. The title of her Ph.D work is "Quality Evaluation of honey using spectroscopic techniques". As a result of her reserach work she has Published the papers in National \& International Journals and also in International conferences.

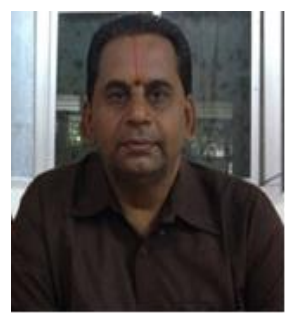

A. Gopal obtained his degree and, post graduation from Madras Christian College, Chennai in the field of Physics with Electronics as specialization. He received his Ph.D from University of Madras during the year 1995 in the filed of electronic-instrumentation and underwent Post Doctoral Fellowship for a period of one year at Oakland University, Detroit, Michigan, USA in 1998. He started his career at CEERI Centre, Chennai as Junior Research Fellow (JRF) and presently working as Chief Scientist \& Scientist-in-charge, CEERI Chennai and also Professor of AcSIR, CSIR. So far he has involved in the design \& developed of twenty industrial application prototype instruments, which has got application towards Paper Industry, Fruit exporting Industries, Baking industries herbal industries. As on date he has published around 90 papers in reputed journals/Conference Proceedings. He has got 12 awards (including Two from IEEE) and also got Prof. LIPTAK award from ISA, USA for his contribution to instrumentation $\&$ automation. He has edited around 23 conference/international conference proceeding materials. He has involved in organizing 15 international conferences and conducted several workshops. Also, he guided several Undergraduate and Post Graduate students of engineering institutions. Presently guiding 8 Ph.D scholars and as a D.C member given technical guidance to around 50 research scholars. Under his guidance two scholars has got Ph.D degree.

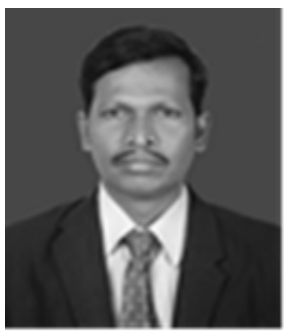

R. Pandian is currently working as an Associate Professor in the Department of Electronics and Instrumentation Engineering at Sathyabama Institute of Science and Technology, Chennai, Tamil Nadu, India. He has graduated from Madras University, Chennai in 1999 with Bachelor's Degree in Electrical and Electronics Engineering. He has obtained his M.E Degree in Applied Electronics from Anna University, Chennai 2007. He has obtained his Ph.D from Sathyabama Institute of Science and Technology. He has Gained 18 years of teaching experience in Engineering colleges which includes 9 years of research experience. He has Published around 35 research papers (indexed in databases like web of science, scopus) in peer reviewed journals and conference proceedings and one patent has granted.Actively involved in research as a coinvestigator of a BRNS funded project in collaboration with IGCAR.Having good exposure and knowledge in both Electrical Engineering and Electronics Engineering related areas.He has completed IGCAR Sponsored Project for Rs 25 Lakhs, Installation of 50 metre multilevel instrumented meteorological tower . He guides 3 Ph.D students. He guided 06 M.E students and $45 \mathrm{~B}$. Tech students. He is acting as reviewer of various journals. 